\title{
Saying the word: Voice and silence in an autoethnography about chronic illness
}

\author{
Rose Richards \\ Language Centre, Stellenbosch University, South Africa \\ E-mail: rr2@sun.ac.za
}

\begin{abstract}
People living with chronic illness experience impairment in various ways, not the least of which is how they are sometimes marginalised by the people with whom they interact. Over the last few decades, as social science research has moved away from the biomedical model, research methodologies have been developed to allow the voices of people with illness or disabilities to be heard and not only to be represented by others. However, these methodologies may not go as far in redressing power imbalances as was hoped, and participants' voices are often still mediated and subjugated to the researcher's requirements. As a person who has lived with a chronic condition all my life, I am concerned about how I am heard and by whom, as this has often affected my self-perception and sometimes even my safety. I am also concerned about doing violence to those about whom I speak and disempowering them further. My doctoral research concerned the problematic of writing about my own experience of a chronic illness. I chose a methodology, autoethnography, that allowed me to write solely about my own experience. In so doing, I was able to consider the complexity of my own academic and narrative voices, individually and in combination. In this paper I explore the methodological and epistemological concerns around my decision to use autoethnography, as well as the sometimes surprising issues I navigated when doing so. One of these issues was the juxtapositioning of different types of texts I had written. In isolation, some of the texts show a clear influence of the very discourses to which I was trying to provide counter-narratives. When read together with other texts, they reveal a complex web of paradoxes, tensions, and silences, which allowed me to generate new narratives and to question assumptions - my own and other people's.
\end{abstract}

Keywords: autoethnography, chronic illness, illness narrative, silence, voice

\section{Introduction}

The insider's view of their own experience of chronic illness is gaining prominence in research as a type of counter-narrative (Nelson 2001) to the formerly predominant medicalised discourse that constructs people as the sum of their symptoms (McDougall 2006; Shildrick 2002). And yet the persistence of the binary of normal/abnormal allows "freak discourse" (GarlandThomson 1997:29) to thrive. This discourse privileges the "normal" over the "abnormal", and 
it seeps into every part of society. Physical disability and illness "[are] complex and demand a personal - and not always comfortable - response. [They seem], often, to exist beyond a barrier of thinking and seeing that encloses disabled people in silence and obscurity" (McDougall, Swartz and Van der Merwe 2006:ix). Normative values are dominant. This means that if you do not conform to them you are silenced. Illness and disability are still constructed as "other", despite many advancements in our understanding of people's experience of these and the increasing numbers of people living with them (Frank 1995; K and Duncan 2006; Kleinman 1988; Marks 1999; McDougall 2006; Sontag 1978; Vehmas, Kristiansen and Shakespeare 2009).

I began my doctoral research as a way of speaking back to power. As a kidney transplant recipient, I often felt as if my story of my own experience was not valued by normative others such as insurance salespeople, medical people, and people who had always been healthy. I wanted to be heard and valued. I wanted justice for what I believed I had been denied by being othered. This othering left me feeling silenced and voiceless and the injustice I felt was hermeneutic injustice (Fricker 2006). I saw that a way of redressing this was to make my voice heard where it counted - in a research context, where I could show that I was an expert too. No longer, I believed as I started my doctoral research, would others "re-interpret" my past and "prescript" my future (Couser 1997:10).

With this in mind, I studied my own experience creating narratives about kidney disease. Because my research was autoethnographic, I also used my narratives to explore and learn about my own preconceptions, and to change and develop my personal and academic perspectives. Autoethnography concerns itself with individual experience. It engages the reader emotionally so that s/he can to an extent identify with what the writer experienced (Muncey 2010). This is achieved through combining academic writing with personal writing - either autobiographical accounts (such as Ellis (1995) or Sparkes (1996)); or aesthetically evocative writing, such as poems or stories (Tillman-Healy (1992) and Wyatt (2008)). Both types of writing, academic and personal, offer epistemological insights and access to experience. In my autoethnography I made sure to privilege both types as equally as possible, so that I did not end up treating my personal narrative as data. The combined effect of these different types of texts creates a new type of understanding, and is useful for capturing the often elusive complexities of identity work.

Telling my story allowed me to create a counter-narrative that went beyond speaking back to power. I discovered the concept of hermeneutic justice (Fricker 2006) after submitting my dissertation. I realised that my autoethnographic journey to achieve this sort of justice had been one towards what Magrini (2015) describes as a more moderate and democratic form of hermeneutics than I had originally envisaged.

In this article I use hermeneutic justice as a way of understanding how my narratives evolved in the chapters of my dissertation concerning childhood kidney disease, dialysis, and life after transplant. Originally my intention had been to correct the hermeneutic injustice I felt had been done to me by others. However, in this article I show how I became aware of committing hermeneutic injustice against myself through the "tyranny of hidden prejudices" (Gadamer in Magrini 2015:2), and I discuss how I dealt with my own prejudices. 


\section{Voice, hermeneutic justice, and autoethnography}

Although I did not yet know the name for it when I commenced my research, my motivation was to find hermeneutic justice (Fricker 2006). Or, as a South African autoethnographer puts it, my aim was to address the question of "What is knowledge and whose knowledge counts?" (Harrison 2009:253). When people try to share lived experiences of medical conditions, they struggle to achieve a sense of hermeneutic justice for various reasons (Fricker 2006; Richards 2008; Weingarten 2001). One is that certain discourses tend to be more valued and privileged. Another is that certain types of research are more widely used and are therefore better understood. When someone wants to share an experience they can be impeded in various ways. They may be unable to say what they want to say because they may not be able to articulate the experience. They may narrate their experience in a way that others may not understand. In addition, what they talk about may be taboo and may therefore be silenced; or they may struggle to find an audience at all. Consequently, the person's voice is lost, unheard, or forgotten. This is known as "voicelessness" (Anthonissen 2009). What results is hermeneutic injustice.

In the latter half of the twentieth century, qualitative researchers began to focus on issues of power and justice. Denzin (2013) describes this period as one during which feminist and communitarian criteria and other ways of challenging the status quo came to the fore. Researchers were considering how they influenced their own research and how it influenced and altered them. This is particularly significant when working with the narratives of others, as one tends to use snippets of narrative to support or illustrate one's points. This can sometimes result in bias, in narratives being subjected to one's own purposes, or in the narrators being silenced. When working with vulnerable groups, one has a responsibility towards them, and one may be able to act as a channel to allow them to be heard in other forums to which they may not always have access (Denzin 2009).

Postcolonial writers such as Pratt (2002) and Lionnet (1989) enjoy autoethnography's way of making a space in which "the centre's self-endowed interpretive monopoly" is challenged by "asserting difference against false claims of sameness" of the "other" (Pratt 2002:34). This allows othered identities to exist and be seen not as derivatives of the dominant culture, but in their own right. In an earlier work, Pratt (1992) describes this as challenging dominant ideologies. For her, autoethnographic texts are heterogeneous and dialectical because they provide different points of entry into themselves for different categories of readers. This allows a space for those not in power to speak back to authority and to elude essentialising categories that may be imposed on them. This is a fertile space for ongoing exploration of meaning.

Evocative autoethnographers (Ellis and Bochner 2000; Ellis, Adams and Bochner 2011; Goodall 2008; Harrison 2009; Poulos 2006; Sparkes 1996) work with autoethnography's potential for helping people - including researchers - to understand their experiences better. They combine evocative writing styles with personal and academic styles for aesthetic and emotional effect. This has many applications; for instance, sharing those experiences with others in similar or different situations to foster dialogue. Writing evocatively can allow one to create a richer narrative that better shows the complexity, ambiguity, and nuances of lived experience. This has proven especially productive for research in education and the experience of medical conditions; where many people's stories may have a ghostly existence outside of the dominant discourses, unspoken and unheard. My research was evocative autoethnography. 
Hermeneutic injustice was the reason I started my autoethnographic research, after being denied health insurance by the bank that housed my mortgage (Richards 2012). I believed that I was denied insurance because I was a transplant recipient and was viewed as high risk. This experience forced me to confront the difference between how I perceived myself (healthy, a good candidate, and normal) and how some others perceived me (ill, a poor candidate, and abnormal). This in turn resonated through events in my life where I came to see that I was not seen at all, but instead consigned to a category of "other"; always doomed to be voiceless and spoken about. So I decided to tell my story. To give it an additional dimension, I decided to create a field of expertise for myself by using autoethnography as a formal research methodology, and to conduct my doctoral research into my own experiences of living with kidney disease.

I thought I knew my story and that it would be easy to assert my voice. I was mistaken. As often happens in autoethnography, the reflexive process changes the researcher and her perceptions. I thus documented this process of becoming as part of my research. Autoethnography challenged me to reconsider my epistemological positioning and to come to accept some very difficult things. It also made me re-evaluate my perceptions of normalcy, essentialising categories, and the meanings of my experiences. In so doing, I discovered my voice and myself. In the following sections I discuss some of what I found.

\section{Making peace with the unspeakable}

I grew up in the 1970s and 1980s, when medical treatment for children living with the consequences of my condition (haemolytic uremic syndrome) was not well developed. We had to rely on therapies designed for adults. For instance, I can recall throughout childhood having to cut up my blood pressure medication with a knife, because the pills were adult doses and child doses did not exist. Although I did not discuss this in my dissertation, I find myself wondering whether this type of ongoing experience does not affect one's voice in some way. Kidney disease is more common in adults than in children, and this was reflected in the therapies available when I was a child. In hindsight, I feel as if this aspect of my life was silencing for me.

I was very much involved in and responsible for my own medical management from the age of nine. At this point, my mother - my primary caregiver - became seriously ill, and I lived with my grandparents for almost a year. Before then, my mother had always tried to empower me by involving me in discussions about my health and teaching me to be aware of what the renal diet involved, what the blood tests were for, and the importance of remembering to take my medication. She also taught me to speak up about my medical concerns in a very specific way, because she was a nurse. In other words, she inducted me into medical discourse. However, medical discourse does not capture personal experience.

Every day I took a pill that I had cut by hand into quarters as well as I could. After we had brought my prescription home from the hospital, the cutting of all the hard tablets took me at least half an hour. These are very tangible reminders for me of a story that I could not articulate. Decades later I can still remember the unyielding surface of the orange-coated tablets and the grinding crunch as the kitchen knife broke through them onto the wooden cutting board. I remember the frustration of pills crumbling or coming out crooked. I had to throw those away because the doses would be wrong. I had to concentrate; I could not talk while doing this. And 
afterwards, I had to count the pieces to make sure I had one for every day. I did not know any other children who did this.

I think much of childhood is unarticulated. An adult looking back perceives the significance of events differently to a child looking forward. At the time I found the pill-cutting boring but necessary, like combing out my long, knotty hair or doing sit-ups in gym warm-up class. At first I did it because the grown-ups wanted me to, but then I did it because I understood it was important for my health. I never spoke of it beyond expressing irritation at the repetitive nature of it or frustration about cutting pills crookedly. The narrative I relate here is an adult one. My use of different ways to write about my experiences and needing to reflect on their intellectual and emotional impact over forty years showed me how my narratives had changed. As an ill child I had to survive; as a healthy adult I have the luxury of being able to philosophise. With these changes came epistemological access of different sorts: as an adult with the luxury of being able to put my energy into reflection, I also can compare my childhood experiences with subsequent experiences, or experiences about which I have learned. This type of knowledge is not static, but develops and adapts (Magrini 2015:10). I dramatised my awareness of the incompleteness of narrative by deliberately leaving the narrative unfinished and by drawing the reader's attention to this.

Reflecting as an adult about my childhood experiences has been a sobering experience. When I wrote the dissertation chapter on my childhood illness narrative I started out expecting to find artefacts to write about, as Muncey (2005) had done when writing about her experience of being a nurse and a single mother. She had used artefacts such as photographs, a childhood book, and her nursing epaulettes around which to construct and discover her counter-narrative (Nelson 2001) to the one she had been told all her life.

I had expected to find several artefacts that would represent that period of my life. I have kept a number of childhood artefacts, including books, photographs, school reports, stories and poems, and school exercise books; but nothing I found in them was symbolic to me of my experience of growing up with kidney disease. In fact, nothing in them indicated in any way that I had a serious medical condition, other than two sentences in my 1979 composition book:

My best food is smoked salmon, jam-tart and pepper mint [sic] creams and roast lamb. But I have got a high blood cholestrol $[s i c]$ and can only eat special diary [sic] products and cut the fat off my meat.

Richards (2012:97)

What was the effect of all those untold stories? As my doctoral research progressed, I came to see that it was not only the narratives of other people that I needed to deconstruct, but also my own. However, this fragment is a curiously taciturn piece of writing when one remembers that I was a self-managing child patient. Paradoxically, the story is in the silence. It is likely that I selected what to tell people. After all, stories do not only depend on the teller, but also on the audience. When one tells a story about illness, one tends to consider what one thinks one's audience wants to hear for a variety of social and cultural reasons (Frank 1995; Weingarten 2001). Moreover, one learns how to tell stories from the stories one hears. Not many stories of the childhood experience of kidney disease are available (Darbyshire, Oster and Henning 2006; Nicholas, Picone and Selkirk 2011; Richards 2008), so I had little to use for my own story growing up. 
So why did I silence my own illness narrative, growing up? Possibly it was fear, because I was afraid of my condition worsening. I was old enough to understand that there was no cure. I have been aware for most of my life that there are topics one does not discuss easily with others. Amongst them are physical difference and physical frailty. Perhaps I did not want to alarm and depress my family any further. Alternatively, it may have been nothing more complex than the fact that I had no other frame of reference. I could not remember life without medical diets, pills, and blood tests. I did not especially enjoy these experiences, and therefore may have wanted to focus on other things in my writing. It could have been a combination of these factors. Whatever it was, I think it would be misleading to assume that even though I was a child I was simply the victim. I was an independent child and keen to manage situations I found unsatisfactory. I see now in writing this article that possibly my silence was a type of counternarrative and an attempt at managing circumstances that were largely beyond my control.

Fortunately, while writing my dissertation chapter about my childhood experiences, I remembered a fragment of a poem one of my fellow paediatric patients wrote. My specialist had it up on the wall of his consulting room along with photographs of his patients, some of them having birthday parties or celebrating their transplants. As a child, I just thought he was a friendly chap who liked us and wanted to remember us when we were not with him. As an adult, I see the poignancy of him being surrounded by his little patients' milestones, when so many of them would not survive to adulthood. Every birthday was a victory. Every transplant was a chance at having a future. I used that memory of another child's counter-narrative to reconstruct a partial narrative of childhood renal disease that helped me understand better what happened to me. I did not, however, explore the paradoxical nature of my silence. Although it rendered me vulnerable, it was also empowering.

My fellow patient wrote a poem about his experiences of being in the paediatric transplant ward:

Buckets full of urine

Syringes full of blood.

If a little extra

Feed the geraniums in the mud.

Richards (2012:108)

Despite (or, paradoxically, because of) my own reticence, his poem stuck in my mind all these years because I saw it on the wall each time I went to the clinic, and because it rather daringly (and pleasingly, for a child) concerned urine and blood samples. So I chose that fragment as my second artefact. I wrote about my lack of artefacts and my silence, and about the challenges of piecing together a fragmented and fragmentary narrative. My principle challenge was trying to recreate the world of a child. I was forced to conclude that I could not really do this, and that although the narrative is set in the past, it exists in the present. I deliberately left it fragmented to represent my memory of the experiences. One piece I did not include was this: When I was a teenager, I drew my doctor a picture of a vampire. He looked sad when he saw it and did not put it up on his wall. He may have been silencing my story, but he understood its meaning. 


\section{4. $\quad$ Finding my voice and losing my story}

I went onto peritoneal dialysis at 21 , after years of declining health. I was relieved and delighted, because I had waited so long to be put on dialysis and had become frail by the time I finally got my catheter. Dialysis made an enormous and almost immediate positive difference to my health. For this reason, the dissertation chapter on dialysis had at first seemed the easiest to write. The period I wrote about in this chapter was the shortest (approximately a year), and I had very definite views regarding how beneficial dialysis had been to me. I noticed at this stage in my writing process that my narrative of dialysis differed greatly from other dialysis narratives I had read, which were predominantly negative (Cojocaru 2007; Faber, De Castell and Bryson 2003; Fox and Swazey 1992; Russ, Shim and Kaufman 2005).

Qualitative dialysis research often involves conducting interviews with dialysis patients and their medical care providers. In these cases, to ensure that the experience and narrative of the person with the medical condition and/or their care provider is represented and that their voices are heard, interviews with different population groups are compared (Fox and Swazey 1992; Russ et al. 2005; White and Grenyer 1999). However, this way of interviewing remains a contested type of research (Allen and Hutchinson 2009; Fontana and Frey 2005). To what extent can one mediate the voice of another, or use snippets of a narrative to make one's own points?

Initially, my contention was that these representations of voice and narrative were too mediated; and that the researchers had not been able to spend sufficient time with any of their interviewees (or, in some cases, co-researchers (see Schipper et al. 2010)) to get at what the interviewees' or co-researchers' stories really were. I judged narratives that seemed overwhelmingly negative towards dialysis (e.g. Fox and Swazey 1992) - a therapy that I considered to be my life-saver - to be simplistic because they were mediated. Determined to prove the dissonant voices wrong, I decided to write my own personal dialysis narrative before attempting anything more theoretical.

After writing my personal dialysis narrative, I wrote up an academic discussion of what my dialysis narrative showed. Because I was confident about my own familiarity with my narrative, I at first wrote up the discussion without referring back to the narrative. However, when I returned to the narrative to find quotes to support my argument, I made a disquieting discovery. My discussion, the linear, logic-driven consideration of the virtues of dialysis, differed vastly in content and tone from my emotional and fragmented personal narrative. The initial academic part showed my experience of dialysis as life-affirming, describing my dialysis line as an "umbilical cord" (Richards 2012:141); while the personal part used metaphors of fear and death (Death becomes "a cowboy" hunting down "an Indian" (me) (Richards 2012:129), and there is a "cold current" of unspoken fear in the dialysis unit (Richards 2012:135)). Although contradictory, both narratives were accurate. I came to see that understanding experience consists in part of juxtaposing conflicting narratives and seeing what their combined effect is. Do they cancel each other out? Is one dominant? Does the author value one type more? Do they tell a different tale when read together?

While the two types of text told conflicting stories, as a whole my personal narrative showed ambivalence to and conflict about dialysis. Its imagery reeked of fear of death and longing for safety. It was also filled with strange silences. While one cannot discuss every aspect of one's 
experience in a narrative, the silences can be telling. Sometimes things are unspeakable. One may not be able to articulate parts of one's experience for various reasons.

One of my omissions, for instance, was much reference to relationships with other people. I was focusing on my feelings about my own experience, and wanted to provide as much detail as possible about that. This meant that I could afford to spend less time on other parts, such as my relationships with fellow patients and care providers. Occasionally I alluded in passing to other people, but I did not explore further. Those relationships were complex and, as the writer, I know that I edited them out of the narrative because they would take too long to explain. One snippet I mentioned briefly was how I felt about fellow patients who did not qualify for transplant. I did not explore this feeling further, saying only:

Those of us who had a chance of getting a transplant viewed those of us who didn't with a mixture of awe and respect, seasoned lightly with pity and horror. These patients were like prisoners serving a life sentence, while we were like prisoners who had to serve a certain amount of time, but who might get out early on good behaviour.

Richards (2012:133)

In my discussion section I noted that I had skimped on exploring my interpersonal relationships at this time:

I also left out the importance of the relationships with other patients, doctors and other care providers, especially the nurses. These relationships sustained me and were on the whole very healing in themselves, compared with my less than satisfactory experiences in the three previous years I spent in the adult renal unit. From the staff and patients in dialysis I received care, support and information which helped me to make my dialysis experience work well for me. So why then did I omit these relationships?

Richards (2012:140-41)

However, I took this no further than explaining that I had tried to keep my narrative as simple as possible so that I could explore some of its themes in detail.

These, briefly, are the tensions I chose to keep subsumed in my dissertation. Some of us survive kidney disease and others do not. This makes survivors like me feel vulnerable for different and painful reasons. We know how easily our health can fail. We also know how few of us survive well. We watch too many of our fellow patients wither and die. Equally difficult for us is the complex ethical situation of being labelled "transplantable", while others we know are labelled "not transplantable". In a world of resource rationing, we will get resources that are denied to others (Davids, Marais and Jacobs 2014; Etheredge and Fabian 2015). Some situations are unspeakable.

For the final version of the chapter, I revised my discussion to include a study of silence and negatives. This created a meta-narrative for me as the writer that allowed me to understand my experience more clearly and to articulate it better. I kept the two conflicting accounts, but contrasted them to show how together they led me to a deeper understanding about the complexity of my situation and my ambivalence towards dialysis. I made my discoveries explicit in the chapter so that the reader could see that the narrative had developed in this way. I needed both an academic discussion and a personal narrative to be able to understand the 
complexity of my dialysis experience. This was the first chapter I wrote, as I had assumed it would be the easiest to write: I could remember many details from the period, and life on dialysis was very structured. The writing of this chapter was a watershed for me. It showed me that I needed to learn to tell my story using different techniques in order to be able to understand it better. It also showed me that my voice had yet to develop, as I had not exercised it much. This influenced how I approached the other chapters: with a much humbler spirit and a more open mind.

\section{Learning to say the word}

Writing the section about life after transplant presented its own challenges. I was writing about events that were much closer in time to where I am now. In some instances, I was still living them. This meant that I found the emotional impact greater, and did not always have the distance to acquire the necessary insight. Remembering my experiences of writing my other chapters, I decided to accept the idea of the narrative being messy, and to use it to illustrate how my experience had felt. I also knew that I should be prepared for surprises. However, I could not truly prepare for the surprise I experienced. After leaving Johannesburg, where I had had my transplant, for the Cape, I had avoided the transplant world for years until starting my research. At this point, I had immersed myself in research, narratives, and transplant events.

I had led a "normal" life for many years, so I was unprepared for what happened when I attended a lecture by Lori Hartwell, a transplant recipient from America. When she told us of her lifelong relationship with kidney disease, I was struck by its hardship and privations, as well as by how visible her illness was. At first I felt relieved and thankful that I had not suffered as she had, and then I was struck by the similarity of our stories. We were about the same age, had fallen ill at about the same time, and had had our transplants for a similar length of time. Hers was her second transplant. She had received her first as a child, which might explain why she was so small. I had been more fortunate, in that I had gone into kidney failure some years later than she had, when I was mostly grown.

My story is not identical with Lori's, but it is similar enough for me to have to confront once again how serious my condition was and in some ways still is. Now it seems I have been doing the same thing my doctor did - telling myself for years that all is well, while walking on a knife-edge between sickness and health.... I could not talk about Lori Hartwell's talk for a day afterwards.... I felt drained and shaken as if I had been in an accident.

Richards (2012:168)

It took me a while to process this, because it changed the way I looked at the narratives I had already written. Strangely, I saw them through an outsider's lens for the first time. On campus, where I worked, I was surrounded by young adults of the age I had been when I was most ill. I suddenly understood what I had been through and how it had scarred my life.

I had no point of reference for my new, healthy life after transplant, because I had never been healthy before. Comparing my adolescent and young adult life with those of the students I taught and spent my time with each day, I could see that my life as a student when I was their age - restricted and not carefree at all - was very different from theirs. I had spent a fair amount of time "passing" (Goffman 1963/1990), making sure I fitted in with the mainstream body of 
students. I had not reflected at the time on why I was doing that, because it was too painful. Once, my dialysis physiotherapist had told me that I had a "handicap". I was enraged. That did not fit my narrative at the time. Mine had been an heroic narrative of passing and overcoming, not one of vulnerability and difference. Now, nearly twenty years later, I could see that the physiotherapist was telling the truth. In the privacy of my living room, I tried out the hated word on my tongue: "disabled". And I wept.

That one word changed the course of my narrative. It unsilenced me. I was forced, by articulating "disabled", to reconceptualise my narrative and to see that I was so invested in "freak discourse" that I had silenced myself for twenty years. My silenced narrative juxtaposed "ill" and "well", "normal" and "abnormal", and the changeable dialectical relationship between them. From this juxtaposition, with all its tensions and paradoxes, emerged my post-transplant narrative.

\section{Telling an old and new story}

During my research I was forced to confront the extent to which my life post-transplant had been an exercise in passing and silencing my own story. I had spoken out against my hermeneutic injustice in a strong voice, but in so doing had found that I had silenced myself more than anyone else had. My voice wavered and I fell silent for a while, needing to gather myself together. It took a while to do this, because I needed to negotiate and construct my identity.

"Dysappearance" is the term Leder (1990) uses for the experience of losing your self-image and seeing yourself through another's eyes as a freak or a monster. When I uttered the word "disabled" in my living room that day, I was shocked and afraid. I felt as if my treasured and hard-earned identity of wellness had been stripped from me and replaced with something horrible and freakish. I felt as if I had dysappeared. Paradoxically, it was at that moment that I was able to start reappearing again for the first time in a very long time. Seeing the extent of my disablement and the extent of my efforts to conceal it allowed me to understand my own narrative better. I came to see that I was both healed and not healed, that I "confounded normative identity" (Shildrick 2002:5), and that this was an acceptable otherness. Through writing in this way, using personal and academic writing dialectically, I was able to learn to value and nurture my otherness (Magrini 2015:6).

This is how autoethnography showed me the way back to visibility. It showed me how to see myself as acceptable and how to embrace parts of my identity from which I had long turned away. It did this by allowing me to explore my story in different ways. The personal writing was just as necessary as the research and analysis. Together these ways of reading and writing allowed me to be inside and outside of my story, to be close and far away, to explore the meanings of concepts and incidents, so that they made sense to me emotionally and intellectually. In other words, autoethnography allowed me to find my voice and to use it.

I can also see now that my silence as a child was sometimes empowering for me. My control of my own medical condition and my silence around it was possibly a way of controlling how much information was allowed out into the world. I made some things secret. They belonged only to me in a world where even the blood could be sucked out of my veins and my innermost workings were discussed by others. However, as my circumstances changed (when I grew older, 
when I became more ill, when I had my transplant), my narrative needed to change as well. When it did not, the empowering silence became disempowering.

As an older person, more distanced from many of the events, I can see that my narrative has been informed by how things turned out. Had I not received a transplant that has survived for over twenty years and experienced what health is like, I would have viewed my childhood differently. Had I not received a transplant or had my transplant not survived, my view of dialysis would probably have been different: not a chance at prolonging life, but a way of postponing death (Fox and Swazey 1992).

What I needed to be able to see so that I could rework my own narrative(s) is that I had othered myself and my disablement as a way of managing uncertainty and ambiguity. I had to understand some of the implications of being an insider and an outsider, a healthy patient with an incurable disease who has lived part of her life on life support and whose situation could change in a moment. I had to explore the inbetweenness of my life and come to terms with it and its changeable nature. I had to understand the nature of my "sore spots" and vulnerabilities. Reappearance is painful. I had to learn to do my own narrative justice and not to force it into a normalising pattern.

\section{Conclusion}

Knowledge, as Magrini (2015:5) shows, mediates between the subjective and objective. It is produced through a form of dialectic and is reflexive in nature. Autoethnography provided me with a route to this dynamic type of knowledge from the less productive polarised position I occupied when I began my research. This type of dialectical inquiry should not only disturb those we perceive as other, but also ourselves (Magrini 2015:6). Autoethnography allowed me to see and to value my own experience. I had to learn to "nurture" my own otherness (Magrini 2015:6) to be able to speak back to the "freak discourse" (Garland-Thompson 1997) that I had internalised and that had silenced me for so long.

I did indeed need to show my own story, but, before I showed it to others, I needed to see it myself. So at present, my narrative is not one of how robustly healthy and normal I am, as I had once wanted it to be, but instead, it reflects how complex my experience is. I have had the opportunity to tell my story to a variety of audiences, and it has spoken to some of them in surprising ways. At the Qualitative Health Research conference in Canada a few years ago, a woman whose grandson had had a lung transplant thanked me for the insights I had shared about battling with my identity, because this helped her understand something of what her grandson was experiencing. In a more recent talk to a group of medical practitioners and researchers, I found myself discussing the possible experiences of conjoined twins. I have spoken to postgraduate psychology students about identity. Recently, I wrote a chapter for a book on educational identity (Richards 2015) on ideas that grew out of my doctoral research. This shows that identity work in autoethnography goes beyond individual identity (Mykhalovskiy 1996).

In these ways, I am starting to be able to fulfil the requirements of socially responsible qualitative research (Denzin 2009). I have been part of a research group that has moved from conducting objective and distanced research into the philosophical concerns behind organ donation to advocating for people with kidney disease. This happened partly because of my 
voice and my ability to share and explain my experiences as a person with kidney disease. The group has recently generated a document for Lawyers for Human Rights (Etheredge and Fabian 2015) that will be submitted to Parliament.

I want to end my article with a story to remind myself that, as abstract as it may be, my work begins and ends in experience. Recently, my renal paediatrician contacted me out of the blue. He was in Cape Town and wanted to meet for lunch. We had not seen each other for a few years, although we have always kept in contact. He is older than my late mother and so must be around eighty years of age, but he seemed unchanged since I last saw him. As we caught up over lunch, our conversation necessarily turned to medical affairs. We have both been involved in patient advocacy, although we came to it through different routes. I was struck by two things: a) we were able to speak as peers and colleagues, and b) my relationship with him (as with my medical condition) is the longest one of my life, including my relationships with my parents. It seems inevitable that our narratives would have met, and that we would have the same ethical goals, although we approach them from different epistemologies. My hope is that if people working in different epistemologies work together we can break some of the silences in chronic illness.

\section{References}

Allen, D. and T. Hutchinson. 2009. Using PAR or abusing its good name? The challenges and surprises of Photovoice and film in a study of chronic illness. International Journal of Qualitative Methods 8(2): 115-128.

Anthonissen, C. 2009. Considering the violence of voicelessness: Censorship and selfcensorship related to the South African TRC process. In R. Wodak and G. Auer (eds.) Justice and memory: Confronting traumatic pasts An international comparison. Vienna, Austria: Passagen Verlag. pp.97-122.

Cojocaru, S. 2007. Glamour, interrupted: How I became the best-dressed patient in Hollywood. New York: Collins.

Couser, G.T. 1997. Recovering bodies: Illness, disability and life writing. Madison, Wisconsin: University of Wisconsin Press.

Davids, M.R, N. Marais and J.C. Jacobs. 2014. South African Renal Registry Annual Report 2012. Durban: South African Renal Society.

Darbyshire, P., C. Oster and P. Henning. 2006. Children's and young people's experiences of chronic renal disease: A review of the literature, methodological commentary and an alternative proposal. Journal of Clinical Nursing 15: 751-760.

Denzin, N.K. 2009. Qualitative inquiry under fire: Toward a new paradigm dialogue. Walnut Creek, CA: Left Coast Press.

Denzin, N.K. 2013. Interpretive autoethnography. Walnut Creek, CA: Left Coast Press. 
Ellis, C. 1995. Final negotiations: A story of love, loss, and chronic illness. Philadelphia, Pennsylvania: Temple University Press.

Ellis, C., T.E. Adams and A.P. Bochner. 2011. Autoethnography: An overview. Forum: Qualitative Social Research 12(1): 1-18.

Ellis, C. and A.P. Bochner. 2000. Autoethnography, personal narrative, reflexivity: Researcher as subject. In N.K. Denzin and Y.S. Lincoln (eds.) The Sage handbook of qualitative research (2nd ed.). Thousand Oaks, California: Sage Publications. pp.733-768.

Etheredge, H. and J. Fabian. 2015. An overview of chronic kidney disease in South Africa Expert witness submission to Lawyers for Human Rights. Johannesburg: WISER Chronic Kidney Disease Working Group.

Faber, S., S. De Castell and M. Bryson. 2003. Renal failure: Towards a sociocultural investigation of an illness. Mind, Culture, and Activity 10(2): 143-167.

Fontana, A. and J. Frey. 2005. The interview: From neutral stance to political involvement. In N.K. Denzin and Y.S. Lincoln (eds.) The Sage handbook of qualitative research (3rd ed.). Thousand Oaks, California: Sage Publications. pp.695-727.

Fox, R.C. and J.P. Swazey. 1992. Spare parts: Organ replacement in American society. Oxford, England: Oxford University Press.

Frank, A.W. 1995. The wounded storyteller: Body, illness and ethics. London, England: University of Chicago Press.

Fricker, M. 2006. Powerlessness and social interpretation. Episteme: A Journal of Social Epistemology 3(1-2): 96-108.

Garland-Thomson, R. 1997. Extraordinary bodies: Figuring physical disability in American culture and literature. New York: Columbia University Press.

Goffman, E. 1963/1990. Stigma: Notes on the management of spoiled identity. London, England: Penguin.

Goodall, H.L. 2008. Writing qualitative inquiry: Self, stories and academic life. Walnut Creek, CA: Left Coast Press.

Harrison, L. 2009. A tinker's quest: Embarking on an autoethnographic journey in learning "doctoralness". In K. Pithouse, C. Mitchell and R. Moletsane (eds.) Making connections: Selfstudy and social action. New York: Peter Lang. pp.253-267.

K, S. and M. Duncan. 2006. Psychiatric disability and social change: An insider perspective. In B. Watermeyer, L. Swartz, T. Lorenzo, M. Schneider and M. Priestly (eds.) Disability and social change: A South African agenda. Cape Town, South Africa: HSRC Press. pp.291-310. 
Kleinman, A. 1988. The illness narratives: Suffering, healing and the human condition. New York, NY: Basic Books.

Leder, D. 1990. The absent body. Chicago, Illinois: Chicago University Press.

Lionnet, F. 1989. Autobiographical voices: Race, gender, self-portraiture. Ithaca, NY: Cornell University Press.

Magrini, J. 2015. Plato's Socrates, local hermeneutics, and the just community of learners: Socratic dialectic as inclusive democratic discourse. Philosophy Scholarship, paper 42: 1-13. Available online: http://dc.cod.philosophypub/42.

Marks, D. 1999. Disability: Controversial debates and psychosocial perspectives. London, England: Routledge.

McDougall, K. 2006. "Ag shame" and superheroes: Stereotype and the signification of disability. In B. Watermeyer, L. Swartz, T. Lorenzo, M. Schneider and M. Priestly (eds.) Disability and social change: A South African agenda. Cape Town, South Africa: HSRC Press. pp.387-400.

McDougall, K., L. Swartz and A. van der Merwe. 2006. Zip, zip, my brain harts. Cape Town, South Africa: HSRC Press.

Muncey, T. 2005. Doing autoethnography. International Journal of Qualitative Methods 4(1): $1-12$.

Muncey, T. 2010. Creating autoethnographies. London: Sage.

Mykhalovskiy, E. 1996. Reconsidering table talk: Critical thoughts on the relationship between sociology, autobiography and self-indulgence. Qualitative Sociology 19(1): 131-151.

Nelson, H.L. 2001. Damaged identities, narrative repair. New York, NY: Cornell University Press.

Nicholas, D.B., G. Picone, and E.K. Selkirk. 2011. The lived experiences of children and adolescents with end-stage renal disease. Qualitative Health Research 21(2): 162-73. Available online: http://qhr.sagepub.com/content/early/2010/09/09/1049732310382789.

Pratt, M.L. 1992. Imperial eyes: Travel writing and transculturation. New York: Routledge.

Pratt, M.L. 2002. Modernity and periphery: Toward a global and relational analysis. In E. Mudimbe-Boyi (ed.) Beyond dichotomies: Histories, identities, cultures and the challenge of globalization. Albany, New York: State University of New York Press. pp.21-47.

Poulos, C.N. 2006. The ties that bind us, the shadows that separate us: Life and death, shadow and (dream) story. Qualitative Inquiry 12(1): 96-117. 
Richards, R. 2008. Writing the othered self: Autoethnography and the problem of objectification in writing about illness and disability. Qualitative Health Research 18(12): 1717-1728.

Richards, R. 2012. "You look very well for a transplant": Autoethnographic narrative and identity in chronic kidney disease, kidney failure and the life post-transplant. Doctoral dissertation. Stellenbosch: Stellenbosch University.

Richards, R. 2016. Subject to interpretation: Autoethnography and the ethics of writing about the embodied self. In D. Pillay, I. Naiker and K. Pithouse-Morgan (eds.) Inside teaching in higher education: South African academic autoethnographies. Rotterdam: Sense Publishers. pp.163-174.

Russ, A.J., J.K. Shim and S.R. Kaufman. 2005. "Is there life on dialysis?": Time and aging in a clinically sustained existence. Medical Anthropology 24: 297-324.

Schipper, K., T.A. Abma, E. Van Zadelhoff, J. Van de Grient, C. Nierse and G.A.M. Widdershoven. 2010. What does it mean to be a patient research partner? An ethnodrama. Qualitative Inquiry 16(6): 501-510.

Shildrick, M. 2002. Embodying the monster: Encounters with the vulnerable self. London, England: Sage.

Sontag, S. 1978. Illness as metaphor. New York, NY: Farrar, Straus, \& Giroux.

Sparkes, A. 1996. The fatal flaw: A narrative of the fragile body-self. Qualitative Inquiry 2: 463-494.

Tillman-Healy, L. M. 1992. A secret life in a culture of thinness: Reflections on body, food and bulimia. In C. Ellis and A. Bochner (eds.) Composing ethnography: Alternative forms of qualitative writing. Walnut Creek, CA: Altamira Press. pp.76-108.

Vehmas, S., K. Kristiansen and T. Shakespeare. 2009. Introduction: The unavoidable alliance of disability studies and philosophy. In K. Kristiansen, S. Vehmas and T. Shakespeare (eds.) Arguing about disability: Philosophical perspectives. Oxford, England: Routledge pp.1-11.

Weingarten, K. 2001. Making sense of illness narratives: Braiding theory, practice and the embodied life. The Dulwich Centre. Available online:

http://www.dulwichcentre.com.au/kaethearticle.html.

White, Y. and B.F.S. Grenyer. 1999. The biopsychosocial impact of end-stage renal disease: The experience of dialysis patients and their partners. Journal of Advanced Nursing 30(6): 1312-1320.

Wyatt, J. 2008. No longer loss: Autoethnographic stammering. Qualitative Inquiry 14(6): 955967. 